\title{
Calculation of Energy Ecological Footprint in Guangdong, China from NPP Perspective
}

\author{
Li Huiyu ${ }^{1, *}$ \\ ${ }^{1}$ School of Economics and Management, North China Electric Power University, Beijing 102206, China
}

\begin{abstract}
To evaluate the ecological level and energy consumption of Guangdong Province, by collecting the related data of energy consumption and land area from 2010 to 2019, the energy ecological footprint and net primary productivity were calculated. The study found that between 2010 and 2019, the energy ecological footprint of Guangdong increased from 119.77 million $\mathrm{hm}^{2}$ to 139.90 million $\mathrm{hm}^{2}$, while the net primary productivity increased slightly. Finally, the study analyzed the specific reasons for these changes.
\end{abstract}

\section{Introduction}

The shortage of ecological resources and environmental damage caused by the massive consumption of fossil energy make the problem of ecologically sustainable development more serious. Sustainable development is the "golden key" to solve the current global problems, and the necessary prerequisite for realizing sustainable development is to attach great importance to the construction of ecological civilization and pay attention to the ecological economy at the same time.

Before putting forward targeted countermeasures for the ecological environment of each region, it is necessary to evaluate the ecological situation and sustainability of the region objectively and accurately. William Rees, a professor of ecological economist in Canada, and Wacker Nagel, a doctoral student $[1,2]$, put forward and improved the analysis method of ecological footprint, which is widely used. After deepening the understanding of ecological footprint, Jason Venetouslis et al. [3] first proposed to combine Net Primary Productivity(NPP) with the ecological footprint, and produced a new improved calculation model.

This paper takes Guangdong Province as the research object. Based on the theory of net primary productivity and relevant data of energy consumption, calculates the energy ecological footprint and other indicators, then, analyzes the reasons behind. Providing a reference for identifying the sustainable development situation of Guangdong Province, formulating urban construction strategies, and realizing sustainable development.

\section{Energy ecological footprint calculation}

\subsection{Concepts and principles}

Energy ecological footprint (EEF) is based on ecological footprint accounting, which refers to the total energy consumption of a certain area and the bio-productive land area occupied by its wastes. The reason why biological productive land is used as a unit to measure the energy consumption of resources is that the plants on the land can provide the productivity needed for other biological and ecological activities in the ecosystem, which is called NPP.

\subsection{Data sources}

The energy terminal consumption data and various ecological land areas in this paper come from Guangdong Statistical Yearbook [4] and the official website of Guangdong Provincial Department of Natural Resources [5], the average low calorific value data of various energy sources comes from General Rules for Calculation of Comprehensive Energy Consumption (GB/T 2589-2008), and the carbon emission values from combustion or consumption of various energy sources are taken from 2006 IPCC Guidelines for National Greenhouse Gas Inventory [6].

\subsection{EEF calculation method}

The regional NPP comprehensively considers various types of bio-productive land and their corresponding net primary productivity, so it is necessary to sum up and calculate various types of land area and NPP in Guangdong Province to obtain the regional NPP, as shown in Eq. (1): 


$$
\overline{\mathrm{NPP}}=\frac{\sum_{\mathrm{j}=1}^{n} A_{j} \times N P P_{j}}{\sum_{j=1}^{n} A_{j}}
$$

Where $\overline{\mathrm{NPP}}$ is the average net primary productivity of all bio-productive lands in the region, $A_{j}$ is the area of bio-productive land $j$, and $\mathrm{NPP}_{\mathrm{j}}$ is the net primary productivity corresponding to bio-productive land $j$. In this study, the NPP of various types of bio-productive land in Guangdong Province used the data calculated by Liu Moucheng et al. [7] to make the calculation results more accurate.

The product of various energy consumption, average low calorific value and carbon emission coefficient in a region is the regional carbon emission. In this study, the net inflow of electricity is used as the base to exclude the calculation of repeated consumption of coal and natural gas during power generation in Guangdong Province, and the $\mathrm{CO} 2$ emission factor data of China's power generation measured by IEA [8] is adopted, which represents the grams of carbon dioxide emitted per kilowatt-hour of electricity production.

The following formula is the calculation formula of carbon emissions, where CE is the sum of carbon emissions generated by regional energy consumption, $u_{j}$ is the consumption of energy $j, c v_{j}$ is the average low calorific value of energy $j, c e f_{j}$ is the carbon emission coefficient of energy $j$, et is the net inflow of electricity, and eef is the carbon dioxide emission factor of power generation.

$$
\mathrm{CE}=\sum_{j=1}^{m} u_{j} \times c v_{j} \times c e f_{j}+e t \times e e f \times \frac{12}{44}
$$

Based on the model hypothesis and the definition of ecological footprint, the EEF can be obtained by comparing the carbon produced by each energy consumption with the regional average NPP:

$$
\mathrm{EEF}=\frac{\mathrm{CE}}{\overline{\mathrm{NPP}}}
$$

\subsection{Calculation results and correlation analysis}

\subsubsection{Carbon emissions and their structure}

According to the above calculation method, the regional energy carbon emissions (Table 1) and emission structure (Fig.1) of Guangdong Province from 2010 to 2019 can be obtained. It can be seen from the table that the overall carbon emissions in Guangdong Province have fluctuated and increased in the past 10 years, with a total increase of $17.57 \%$. In 2019, the total carbon emissions were close to 100 million tons, which mainly consisted of raw coal, gasoline, diesel and imported electricity, which contributed $70.36 \%$ of the total carbon emissions. Among the top ten energy categories, except for the carbon emissions of coal and fuel oil have decreased obviously, and the carbon emissions of diesel have not changed obviously, but the carbon emissions of other energy sources are all rising steadily.

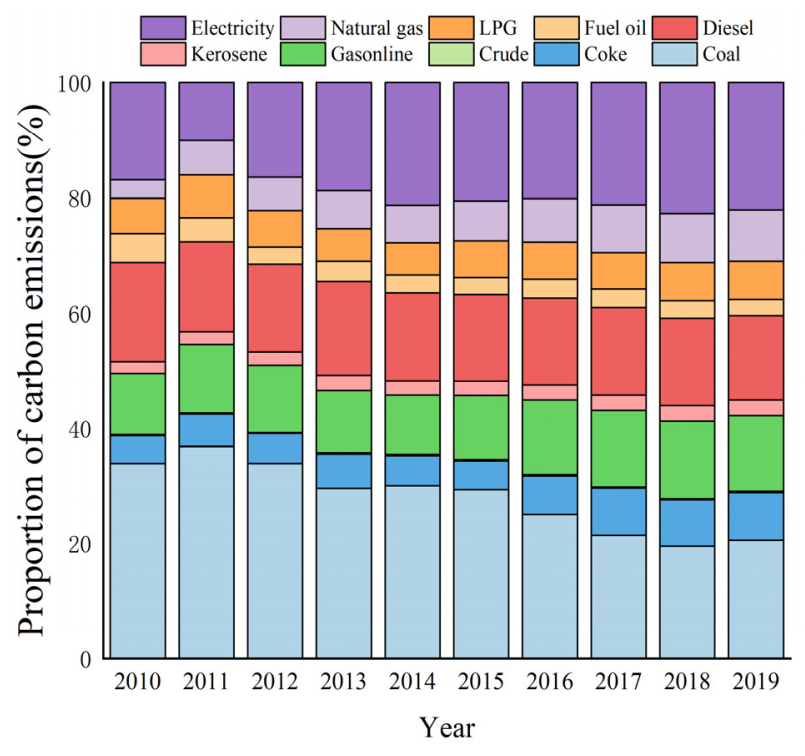

Fig.1. Carbon emission structure

Table 1. Carbon emissions from energy sources in Guangdong Province from 2010 to 2019 (unit: 10,000 tons)

\begin{tabular}{cccccccccccc}
\hline Year & Coal & Coke & Crude & Gasoline & $\mathrm{e}$ & Diesel & Fuel oil & LPG & Natural gas & Electricity & Total \\
\hline 2010 & 2820.91 & 403.49 & 14.65 & 886.90 & 170.45 & 1426.76 & 423.20 & 504.76 & 263.06 & 1408.00 & 8322.20 \\
2011 & 3034.42 & 458.44 & 14.10 & 985.53 & 182.53 & 1283.43 & 342.46 & 601.88 & 489.11 & 834.70 & 8226.60 \\
2012 & 2971.63 & 452.65 & 13.34 & 1026.87 & 205.24 & 1324.62 & 271.39 & 548.80 & 497.74 & 1443.76 & 8756.04 \\
2013 & 2410.28 & 485.05 & 17.37 & 875.55 & 218.89 & 1322.74 & 286.01 & 463.02 & 530.08 & 1529.32 & 8138.31 \\
2014 & 2667.69 & 463.26 & 17.70 & 908.26 & 225.92 & 1348.65 & 273.13 & 505.49 & 571.88 & 1885.55 & 8867.52 \\
2015 & 2666.19 & 450.80 & 19.37 & 1003.64 & 231.40 & 1361.77 & 265.78 & 583.11 & 620.29 & 1863.28 & 9065.63 \\
2016 & 2375.46 & 649.74 & 19.59 & 1227.17 & 246.43 & 1437.67 & 309.72 & 621.91 & 711.22 & 1915.65 & 9514.56 \\
2017 & 2021.69 & 781.28 & 19.59 & 1251.09 & 252.79 & 1434.65 & 305.91 & 604.30 & 776.22 & 2004.88 & 9452.40 \\
2018 & 1852.03 & 774.80 & 16.42 & 1271.70 & 258.48 & 1438.34 & 289.23 & 627.59 & 809.85 & 2156.07 & 9494.52 \\
2019 & 2009.71 & 817.90 & 21.97 & 1276.32 & 264.18 & 1438.78 & 276.02 & 644.07 & 876.17 & 2159.45 & 9784.56 \\
\hline
\end{tabular}


Combining Fig. 1 to further analyze the changes in the carbon emission structure of Guangdong Province over the past 10 years, according to the actual situation, it can be concluded that: (1) the proportion of natural gas used in Guangdong Province has increased significantly, from $3.16 \%$ to $8.95 \%$ of the total carbon emissions, and natural gas has the characteristics of large heat production and small sewage discharge, which makes it bear more carbon that should have been emitted by other energy sources; (2) the total carbon emission ratio of oil energy has not fluctuated much in the past 10 years, and it contributed more than $40 \%$ of carbon emissions every year. Among them, gasoline and kerosene with relatively low carbon emission rate continue to grow, while diesel and fuel oil are suppressed; (3) since the implementation of the 13th Five-Year Plan for Energy Structure Adjustment in

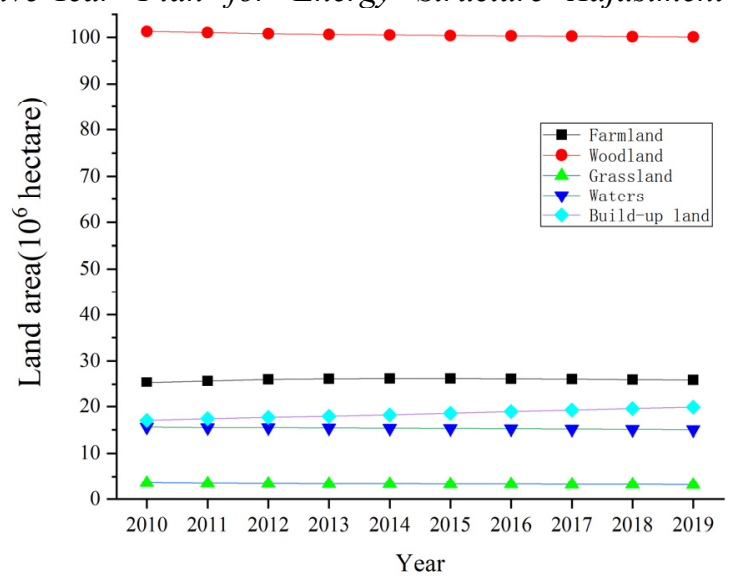

Guangdong Province, the coal consumption has been strictly controlled, and the speed reduction is also increasing. Compared with 2010-2014, the speed reduction in 2015-2019 has increased by about 3.5 times.

\subsubsection{EEF and NPP}

Based on calculating the carbon emissions, the land situation of Guangdong Province is further calculated and analyzed. According to the land area data published by the official website of Guangdong Provincial Department of Natural Resources, the change of land area and the changing trend of regional NPP and EEF in Guangdong Province are output (Fig.2).

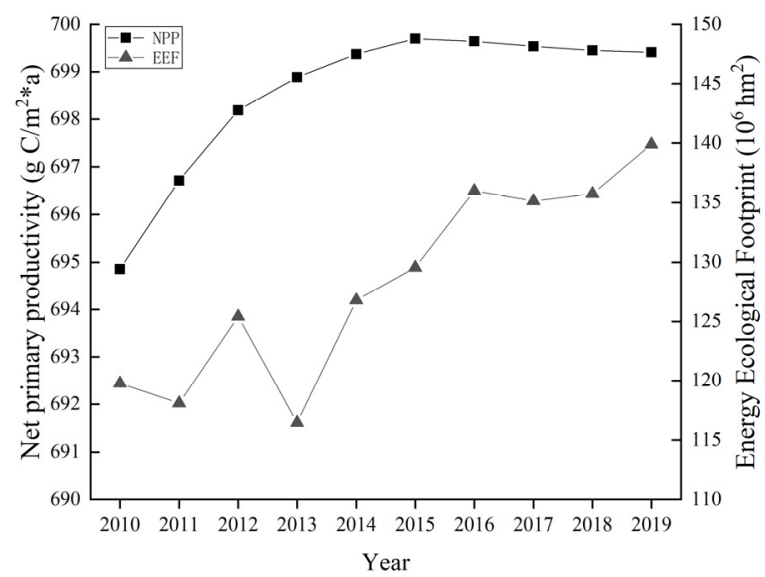

Fig.2. Changes of bio-productive land area, EEF and NPP in Guangdong Province

From the above output results and related data, it can be seen that the area of construction land in Guangdong Province has increased greatly in recent years, with an increase of $16.88 \%$, which is the only land type with an obvious increase among the five types of bio-productive land, and the increase of its area is mainly obtained by sacrificing the water area. In addition, Guangdong province has a long summer and abundant heat resources, with annual rainfall exceeding $1,500 \mathrm{~mm}$ in most areas, so the NPP of cultivated land, grassland and water area in the region is higher than the world average level, and Guangdong province pays more attention to the protection of cultivated land, and has issued and implemented the assessment method for defining the responsibility target of cultivated land protection for many years, Therefore, in recent ten years, the provincial average NPP has not decreased due to industrial production or land development, but showed a slight upward trend.

During 2010-2019, the EEF in Guangdong Province increased with an average annual growth rate of $1.74 \%$. It should be noted that according to the Guangdong Statistical Yearbook, energy consumption in Guangdong Province is concentrated in Guangzhou, Shenzhen and Dongguan, taking electric power consumption as an example, the power consumption of the three cities is about three times the average of the provinces; if divided into economic regions, the Pearl River Delta region consumes more than two-thirds of the province's energy. It can be seen from the above that there is a regional problem of the gap between rich and poor in ecological supply and demand in Guangdong Province. In the future, the carbon emission pressure in high energy-consuming areas can be appropriately dispersed to areas with loose surrounding environmental pressure.

\section{Conclusion}

By summarizing the data of Guangdong from 2010 to 2019 and using the NPP energy ecological footprint calculation model, the energy ecological footprint of Guangdong Province is still growing, and the growth rate has slowed down in recent years, mainly due to the reduction of raw coal use and the increase of natural gas input. At the same time, the NPP of Guangdong Province began to decline slowly after reaching the peak in 2015 . As the most populous and affluent Province in China, Guangdong Province needs a lot of energy and ecological consumption for its economic and social development, which is inevitable. Despite this, Guangdong provincial government can start from the structural adjustment to promote energy conservation and emission reduction. For example, the implementation of urban non-coalification policy to accelerate the withdrawal of coal and coke; coordinate the balance of energy consumption and output in each region of the province, and share the ecological pressure with the surrounding areas; or to find the balance between urbanization and energy conservation and emission reduction, economic development. In general, in 
order to achieve China's carbon peak and carbon neutral goals, the energy ecological footprint control of Guangdong Province will be the top priority.

\section{References}

1. R. William, W. Mathis, Environmental Impact Assessment Review, 16, 223(1996)

2. R. William, Environment and Urbanization, 4, 121(1992)

3. J. Venetoulis, J.Talberth, Environment, Development and Sustainability, 10(2008)

4. Guangdong Provincial Bureau of Statistics, Guangdong Investigation Corps of National Bureau of Statistics, Guangdong statistical yearbook, (2020)

5. Guangdong Provincial Department of Land and Resources, http://nr.gd.gov.cn/gkmlpt/index, (2020)

6. IPCC, 2006 IPCC Guidelines for National Greenhouse Gas Inventory, (2006)

7. L. Moucheng, L. Wenhua, X. Gaodi, Chinese Journal of Ecology, 29, 592(2010) 